\title{
Commentary: Setting the theoretical stage
}

\author{
Slawomir J. Magala \\ Rotterdam School of Management, \\ Erasmus University, \\ Burgemeester Oudlaan 50, (Room T8-01), \\ 3062 PA Rotterdam, The Netherlands \\ E-mail: smagala@rsm.nl
}

\begin{abstract}
This a commentary on the paper by Fink and Mayrhofer published in European J. Cross-Cultural Competence and Management, Vol. 1, No. 1, 2009, pp.42-65.

Keywords: epistemology; culture; values; culture standards; personality profiling; cross-cultural competence in management; tacit assumptions; viable systems; cultural programs; theoretical canons; cross-cultural competence.

Reference to this paper should be made as follows: Magala, S.J. (2010) 'Commentary: Setting the theoretical stage', European J. Cross-Cultural Competence and Management, Vol. 1, Nos. 2/3, pp.140-145.

Biographical notes: Slawomir J. Magala was educated in Poland, Germany, and the USA. He is currently holding a Chair in cross-cultural management and chairing a Department of Organizational Sciences and Human Resource Management at the Erasmus University in Rotterdam. He has published numerous books, e.g., Georg Simmel, Class Struggle in Classless Poland (under the penname of Stanislaw Starski), Cross Cultural Competence (Routledge, 2005), The management of Meaning in Oganizations (Palgrave, 2009). He translated Susan Sontag, John Barth, Samuel Beckett, Norman Mailer, Alfred Whitehead and George Ritzer into Polish and is the Editor-in-Chief of Journal of Organizational Change Management.
\end{abstract}

Setting theoretical stage is never neutral. We know that the choice of assumptions and fundamental metaphors will influence our theoretical scaffolding, that 'stage design' will determine plausible "plots" for interactions and cognitive inventions. A Marxist will never stoop to decipher hidden agendas of unconscious drives prompting neurotic behaviour, while a Freudian will never reconstruct emergent social movements as the first birth pangs of a new phase in class struggles. A McNamara would never study the impact of a multinational corporation on local communities on Indonesian islands, because his theory of rational management had a 'one size fits all' tag (so it was supposed to work equally well in Detroit and Vietnam, for GM and for Pentagon). The problem with 'setting the stage' is therefore that we never begin with a clean slate (although either Hume or Kant, or even the structuralists might have hoped so) and that we will never be able to maintain neutrality vis a vis major social, economic, political or cultural movements, forces, actors or agencies. Research audiences reading or hearing our professional communications are bound to see our new stage design against the background of the past dominant mainstream designs of cross-cultural and intercultural theorising, namely Hofstede's canon, Schwartzian schemes or GLOBE's clusterings. 
The paper on 'Cross-cultural competence and management - setting the stage' by Gerhard Fink and Wolfgang Mayrhofer (both from the Vienna University of Economics and Business) will thus be perceived as a successive shot in a new battle for defining the contours of the discipline. Thus, readers of the paper will read it against the background of the forthcoming reshuffling of sociopolitical priorities (aid to the postcolonial countries? Yes, but sustainable and controlled from bottom up to prevent local elite's waste of potential developmental resources) and against the melody of whispered cultural programs improvised for the emergent social movements and changes (do we always need to have symbolic figureheads commanding top of professional bureaucratic hierarchies in order to represent the interests of the underdogs?).

Are the abovementioned Austrian authors aware of these potential adventures of their text in the hands and minds of their prospective audiences? When starting to review 'Cross-cultural competence and management - setting the stage', I had almost made a Freudian slip and added the name of Maurice Yolles to the two abovementioned authors. The slip would have been easily explained by the fact that the authors acknowledge the assistance offered by Yolles and Dauber and even more so by the fact that they adapt the 'social viable systems model' worked out by Yolles in 2006. Their success depends crucially on the adequacy of this model for their purposes and on their bridging of the gap between two views:

a that culture is a relatively stable and identifiable causal factor triggering human behaviour (Hofstedian canon)

b that culture is a mutable flow of action resources, which is co-shaped by social interactions, modified by learning loops and continuously corrected by self-reflexive actions (which is what McSweeney and some other participants of the Rotterdam 2007 Conference on 'Cross-cultural Life of Social Values' had postulated).

Apart from McSweeney, Terence Jackson belonged to the most vocal representatives of a critical twist in the cross-cultural studies, and was quite straightforward, although diplomatic and courteous in his critique of the canon:
"Hofstede's theory may be problematic from both a methodological/theoretical, and practical view when applied to the 80 percent of the Globe we term Developing. It is necessary to break out of an epistemic paradigm and a 'view from nowhere' 1 in order to focus on multiple layers of cultural interfaces within power dynamics that influence the nature of hybrid organizations and individual cultural identity. Cross-cultural values theory provides a blunt instrument in Africa, does not take into account global dependencies and is not able to analyze local perceptions of reality within the context of these dependencies." (Jackson, 2007)

Fink and Mayrhofer are well aware of this critique, since they belonged to the co-organisers and participants of the Rotterdam Conference on 'Cross-cultural Life of Social Values'. They would have thus agreed that there is an urgent need for a major overhaul of our theories of cross-cultural values and for the development of a new approach towards their illegal underground trafficking. These sentiments had recently been expressed by the undersigned in the following way:

\footnotetext{
"The standardization of research around the isolated individual as a sovereign decision-maker has prevented us from participative research in making more socialized models available and relevant. We have traced the origins of demonization (angry mobs versus rational individuals) to Cold War academic policies, which were developed against the background of history conceived as
} 
a sequence of never-ending sessions of single frozen protagonists routinely enacting, reiterating, copying, repeating the prisoner's dilemma and simply requiring superior analytical skills to win the future (as if it were a game of chess, a blockade of Berlin, a Cuban missile crisis, a war by proxy in Angola or Afghanistan) and to continue winning it over and over again.

There is no cunning passage within our institutional history, which would lead us to the city on the hill or to a single best option for which there is no alternative among a cluster of individuals who make choices as if there were no such thing as society. Values and meanings cannot be entirely outsourced; responsible citizens have also to be part-time "economists of worth'." [Magala, (2009), pp.219-220]

Fink and Mayrhofer make a very important choice at the very outset. They decide to accept the 'Maruyama universe' of classification, relation and relevance (roughly - cognition and knowledge production, interactions and institutionalisation, and meaningful action) and to follow the latest development of Maruyama's theoretical insights by the British researcher, Maurice Yolles. As far as adequacy of the the Yolles model is concerned, the authors begin on a promising note. Their reference to Maruyama is welcome and the latter's epistemological distinction between 'classificational', 'relational' and 'relevantial' universes of meaning promises a richer theoretical language than we are used to in the sciences of management and organisation. In the first universe of Maruyama, there are inventories and definitions, and mostly 'normal scientific output'. In the second, we encounter events, flows and interconnections, which manifest some patterning and some routines; business as usual. In the third, we penetrate the depths of emotional and motivational commitment which design levels of relevance of flows of events and interactions for social actors and thus indeed 'set the stage' for tragedies, comedies and everything in-between these two extremes (which probably includes history repeating itself as a farce, as Marx would have it). The authors have high hopes: they hope to explain - with the help of the Yolles' model of 'social viable system' - not only the influence of values on our thinking and relating to others but also the reverse influence of our self-reflexive interactions and re-interpretations upon the values themselves (which are thus depicted - values, of course - as malleable and impacted by the tempo, intensity and contexts of our learning and self-correcting). When evaluating the promises and looking at the Yollesian scaffolding, one is tempted to make two remarks:

- First, one wishes for a closer explanation why the process outlined in social viable systems model is 'recursive rather than linear'. Intuitively it is clear, we all 'feel' that it is indeed so, but a simple category of a feedback is not enough.

- Second, one wishes for a better explanation of the correspondence between three ontological domains (cultural values, personal identities and behavioral acts) and four processes (values being translated into actions, intellectual reflections being translated into action, outcomes of actions being assessed by individuals, social systems responding to individual assessments). Most relevantly: what is the winning combination of Maruyama's chief building blocks of theoretical stage; epistemological principles/levels/universes -as far as rendering of these correspondences and intertwined mutual impacts goes?

Yolles and Iles have once suggested that beliefs (holding values and measuring the world against them) are the steel skeleton of knowledge [cf. Yolles and Iles, (2006), p.628]. Around this newly erected steel frame, a thinking individual personality pours concrete 
and constructs a house - surrounding the steel frame with concrete walls of processed information. Knowledge with values is the core, information processing is organised around these values and accompanying knowledge. Then comes the office furniture for our newly built house - empirical data, which trigger action and make our thinking (knowledge and information processing) relevant for the world, for ourselves and for the others. Powerful vision; but why this strict Trinitarian hierarchy, resembling Popperian triple worlds of objective knowledge (though Yolles' model is much better tuned to a pragmatic study of social action)? Incidentally, I am not sure why a 'blue collar worker' on p.49 in Figure 2 about levels of analysis is classified as 'individual', along with females and managers or expats. A random mistake or some new vision of blue-white collar distinctions in the era of outsourced office services, performed by call centres in India?

Nor is this all. When we are about to reconstruct the beliefs, uncover the unconscious assumptions, mine for values as espoused by individuals and communities, we are bound to encounter the problem which baffled the structuralists, especially those, who wanted to follow Levy-Strauss in ethnography or Barthes in semiology, early Chomsky in linguistics or late Althusser in sociology of working class movements.

On p.51, the authors quote Welzel/Inglehart and Esmer/Pettersson, summing their views up in the following way: "since the 1920 s or 1930 s most societies moved from survival and traditional
values towards self-expression and secular rational values."

The dates strike me as awkward and random at best. It is true that 1930 s were significant for the Western societies for one very important reason: while economic crisis sharpened social friction between the middle class and the unemployed poor, the USA responded with New Deal, but Germany with a Nazi war economy and Russia with Stalinist genocide. What merits attention is the simultaneous expansion of universal education (it was in the 1930s that most European societies could start claiming that almost all adult citizens could read and write) and the facility with which totalitarian propaganda made grand terror on behalf of a master race or master class possible. This was the industrialisation of politics, war and death (Soviet Gulag and German Nazi concentration camps). The only recent attempt to understand these and similar processes, which might lead to a general reshuffling of values in generational cohorts had been undertaken by Goran Therborn in his fascinating study of the 'patriarchal burden' of the 21 st century, inherited from the 20th. Therborn concludes (choosing 1968 rather than 1930s as the turning point):

"What came out of the ' 1968 ' changes was not so much the beginning of an end to the Western socio-sexual order; as an end to the twentieth-century industrial standardization of it, and of the human life-course in general; an end to temporary standardization around a low-level (but above replacement), a maintenance of strict sexual norms combined with increased possibilities of avoiding sexual accidents, a high marriage rate, and marrying concentrated to a short and historically early age-span, a prosperous decrease of inequality among class households, a wide, inter-class social diffusion of family norms and housewife marriage, with the coming of liveable pensions and of standardized retirement. In the two decades right after WWII this pattern of homogenization and standardization reached its zenith. Since then all these features have become more variable." [Therborn, (2004), pp.314-315] 
Fink and Mayrhofer limit themselves to the above quote on the 1920s and 1930s as the years of the shift to non-traditional values. Hard to believe in view of what was happening at the time in, let us say, Germany (Nazism was the most traditionalist reversal of modernist value systems imaginable), Soviet Union (secular religion of Orwellian size imposed by autocratic state was even more anachronistic, though it was cloaked in modernist propaganda jargon) or USA (reinvention of 'go west young man' - and listen to fireside chats by uncle FDR - with strong reliance on religious communities actually ushered in a very secular 'new deal' after Great Depression). Thus, a reader may be sceptical: value changes in Germany after WWII? Perhaps. But if we are talking about non-traditional value hierarchies, then rather around 1968 and between Joshka Fischer's struggles with the anti-riot police on the streets of Frankfurt and the same Joshka Fischer's entry to the Ministry of Foreign Affairs of reunited Germany. In Russia? From Gorbatchev to Putin, then back to good old Stalin as a cruel but in the long-run comfortingly great Father of all Russians. Value changes? Perhaps. But the authoritarian quasi-party of Putin, 'United Russia' is as traditional as one can imagine (though its hired thugs, or young criminals terrorising political opponents and killing journalists, are paid in cash, not with party careers). Value changes in the USA? If we are to believe Sennett, in the '50s and ' 60 s education was the preferred venue of upward social mobility, in direct continuation of the New Deal and GI bill policies. Things went sour in inner cities after 1968 - but more because of the racial riots than student protests. Thus, not in the 1920s and 1930s (cf. Sennett, 2003) $)^{2}$. So much for sensitivity to historical context.

On p.54, the authors try to enlist big five dimensions of personality into their fighting army of winning concepts in cross-cultural research. Personality itself is a very suspect concept (perhaps even more shaky than identity), and its matrix-like role with respect to cultural dimensions or Globe's modified dimensions deserves a much more justified treatment. I do not see what is gained by including the personality traits in this form, but would like to be convinced by concerned authors that they are right in putting them there.

Same holds true for MBTI model; potentially OK, but inserted as if dropped on a parachute behind enemy lines.

Summing up: I hope we shall be able to emerge with something more than rehashed cultural standards or refreshed and more sophisticated national stereotypes and I basically sense that the authors are moving in a promising direction. However, in their zest for winning allies in their struggle they tend to take too much for granted. Convince me that you are not.

Wish you good luck in this endeavour!

\section{References}

Jackson, T. (2007) 'From cultural values to cross-cultural interfaces: Hofstede goes to Africa', Unpublished paper for the International Conference 'Crosscultural Life of Social Values', Rotterdam, 18-19 May 2007.

Magala, S. (2009) The Management of Meaning in Organizations, Palgrave Macmillan, Basingstoke and New York.

Nagel, T. (1989) The View from Nowhere, Oxford University Press, Oxford and New York.

Sennett, R. (2003) Respect in a World of Inequality, W.W. Norton \& Company, New York and London. 
Therborn, G. (2004) Between Sex and Power. Family in the World, 1900-2000, Routledge, London and New York.

Yolles, M. and Iles, P. (2006) 'Exploring public-private partnerships through knowledge cybernetics', Systems Research and Behavioral Science, Vol. 23, pp.625-646.

\section{Notes}

1 Jackson refers to the title of the famous essay (and a subsequent book) by Thomas Nagel (cf. Nagel, 1989).

2 'In society, and particularly in the welfare state, the nub of the problem we face is how the strong can practice respect towards those destined to remain weak' [Sennett, (2003), p.263]. 